\title{
JUDÍOS HISPÁNICOS Y MUNDO RURAL *
}

DAVID ROMANO

Universidad de Barcelona

\section{ÍNDICE}

0. Introdución

1. La posesión de tierras

1.0. Generalidades

1.1. Situación geográfica de las tierras

1.2. Medios de posesión y transmisión de tierras

1.3. Tipos de tierras

1.4. Las tierras en los Repartimientos

2. El cultivo de las tierras

2.0 Consideraciones generales

2.1 Propiedades de tamaño medio: explotación ganadera

2.2 Pequeños cultivadores judios

2.3 ¿Fue la agricultura ocupación principal de los judios?

3. La residencia rural

3.0. Preliminares

3.1. Inexistencia de población rural judía

3.2. Falsedad de las huellas de la toponimia

4. Conclusiones

* En la realización de este trabajo me he beneficiado parcialmente de la ayuda del proyecto $n^{2}$ PB87-0011-C02-01 de la Dirección General de Investigación Científica y Técnica (DGICYT) del Ministerio de Educación y Ciencia. La primera redacción fue presentada en el congreso celebrado en Jerusalén (16-24 agosto 1989), con el título Los judlos y el campo en los estados hispánicos. Se ha publicado en los "Proceedings of the Tenth World Congress of Jewish Studies", division B volume II: "The History of the Jewish People» (Jerusalem 1990), págs. 135-142.

Abreviaturas utilizadas:

BAER, JCS I y II = F. BAER, Die Juden im christlichen Spanien. Urkunden und Regesten, 2 vols., Berlin 1929-1936 (reimpresión Greg, England 1970).

Romano, Habitats = D. Romano, Habitats urbains des juifs hispaniques, en el coloquio "Les Sociétés urbaines dans la France Méridionale et la Péninsule Ibérique au Moyen-Age», Pau (Francia), 21-24.9.1988 [en prensa].

Romano, Les juifs de Catalogne = D. Romano, Les juifs de Catalogne aux alentours de l'an Mil, en *Colloque International Hugues Capet, 987-1987», Barcelona 7.1987 [en prensa]. 


\section{INTRODUCCIÓN}

La cuestión que voy a plantear ahora la he tratado parcialmente en otras ocasiones, la más reciente de ellas en la ponencia Habitats urbains des juifs hispaniques, presentada el año pasado en el congreso de Pau. Y porque allí el tema era precisamente el opuesto, es decir, la ciudad, sólo expuse incidentalmente la inexistencia de hábitat rural. Aquí desarrollaré un esquema más completo y más sistemático, pues no sólo me ocuparé del hábitat sino también de la relación de los judíos hispánicos - más que probablemente lo mismo cabría decir de los no hispánicos - con el campo ', que puede analizarse al menos en tres aspectos: la posesión de tierras, el cultivo de esas tierras y la residencia rural.

Un problema de difícil solución - me lo planteó hace tiempo Miguel Ángel Ladero- es decidir qué debe entenderse por rural y qué es urbano en la Edad Media: a algo de eso aludo en el $\S 1.1$, pero el tema general desborda los límites de este estudio. La verdad es que las fuentes que se pueden utilizar no son muy reveladoras: los documentos históricos, que son los que dan la precisión cronológica y geográfica, callan mucho sobre el aspecto que ahora me interesa; los textos, siempre elaborados, me resultan sospechosos para cualquier intento de reconstrución histórica.

Además, pienso en afirmaciones tajantes y para mí no solamente desorientadoras sino falsas acerca del cultivo agrícola y eso de que los judíos eran "conocedores de técnicas de viticultura" o de que "se les consideraba excelentes viñadores». ¿Derivan de interpretaciones abusivas de los documentos? ¿O no son más que afirmaciones subjetivas? No sé si influye en esta actitud el recuerdo de la ocupación principal de los judíos en tiempos bíblicos o la imagen del Israel actual. Frente a esta actitud de quienes contestarían afirmativamente a la cuestión de las relaciones de los judíos con el campo en la Edad Media, pienso en un factor negativo: el peligro, el peligro físico que el aislamiento rural supone para el judío. Es

1 Véase B. LEROY, Les juifs et le monde rural dans la vallée moyenne de l'Èbre dans la deuxième moitié du XIV siècle, en «Proceedings of the Ninth World Congress of Jewish Studies, division B, vol. I: The History of the Jewish People", Jerusalem 1986, págs. 83-90. 
precisa una agrupación por motivos de autodefensa, en un medio a veces hostil, y en todo caso no excesivamente favorable ${ }^{2}$.

Lo que diré es válido para todas las épocas y para todas las naciones y estados hispánicos; pero, por razón de especialidad y por supervivencia de documentación ${ }^{3}$, mis ejemplos se referirán sobre todo a la Corona de Aragón.

\section{LA POSESIÓN DE TIERRAS}

\subsection{Generalidades}

Adelanto ya que la primera cuestión, o sea, la de la propiedad de tierras por judíos, tiene una respuesta, sin vacilación, positiva.

Los documentos son abundantes e inequívocos en todas las naciones y estados hispánicos, aunque no sean todo lo detallado que se desearía. Lo que sí parece indudable es que los judíos poseyeron pequeños terrenos o parcelas, quizás de mínima extensión, pero nunca grandes posesiones rústicas, a menos que quieran considerarse así las tierras obtenidas en los Repartimientos ${ }^{4}$ de zonas recién conquistadas a los musulmanes.

\subsection{Situación geográfica de las tierras}

No parece que hubiera grandes extensiones rurales propiedad de judíos. Al contrario: en todos los casos conocidos se trata de pequeños terrenos, muy diseminados pero siempre o casi siempre cerca de núcleos urbanos.

En realidad, creo que de ningún modo puede hablarse de propiedad rural -para los cristianos, sí- sino de lo que yo suelo llamar semirrural y que hoy se denomina "subu bana». Se trata de tierras y viñas situadas en la periferia de una ciudad; pero aparte de su

${ }^{2}$ No sé hasta qué punto es cierta la afirmación de que la práctica del judaísmo exige la agrupación de sus fieles, como dije en otra ocasión (véase Romano, Habitats, $\S 3.0$ ), pues pienso que cumplir las prescripciones judías también puede hacerse individualmente.

${ }^{3}$ Sobre las fuentes subsistentes véase D. Romano, Les juifs de la Couronne d'Aragon avant 1391, "Revue des Etudes Juives» CXII (1982) 169-182.

4 Véase $\$ 1.4$. 
situación, que las pone en relación directa con el hecho urbano, desde los demás puntos de vista son tierras de carácter rural. (Subrayo: tierras pero no hábitats).

En este sentido el caso de «Cubellas» es significativo. Contra la afirmación de que se trataba de una "colonia judía alejada de Barcelona", creo haber demostrado. ${ }^{5}$ que no era una propiedad rural sino simplemente una propiedad semirrural (en el territorio de Barcelona).

Son piezas de tierra alguna vez próximas o lindantes entre sí, distribuidas entre parcelas propiedad de cristianos. Los ejemplos más antiguos recopilados son los de Barcelona en los siglos X-XII ${ }^{6}$, pero podrían multiplicarse fácilmente para cualquier época y país, simplemente recurriendo a algunos repertorios documentales.

\subsection{Medios de posesión y transmisión de tierras?}

Documentalmente ya desde épocas remotas ${ }^{8}$ hay constancia de ventas de tierras, y también de compras, aunque éstas sean mucho menos numerosas ${ }^{9}$, pero parece bastante evidente que para vender tierras había que haberlas adquirido antes.

${ }^{5}$ Romano, Les juifs de Catalogne, § 1.2.1.1 y doc. 4.

6 Además de los datos recogidos y elaborados en Romano, Les juifs de Catalogne, especialmente en el $\S 1.2 .1 .2$, véase F. de A. DE Bofarull y SANS, Jaime I y los Judios, en "[Primer] Congreso de Historia de la Corona de Aragón", Barcelona 1913, págs. 820-821. La primera parte de este estudio se titula -así corre la cita en muchas bibliografias, por ejemplo en Singerman - "Los judíos en el territorio de Barcelona en los siglos X, XI y XII". Véase también J. M." Millás ValliCrosa, Posesiones inmuebles rústicas, propiedad de los judios en los alrededores de Barcelona, "Sefarad" XXVII (1967) 64-69, resumen basado en los documentos en hebreo que él mismo publicara en 1927.

${ }^{7}$ Lo que voy a decir en este apartado se refiere a tierras, pero también es aplicable a las posesiones inmuebles urbanas.

${ }^{8}$ El documento más antiguo que conozco es del 5.10.973: contiene el texto latino y una línea en hebreo. Fue publicado por M. Schwab y J. Miret y Sans, Le plus ancien document à present connu des juifs catalans, "Boletín de la Real Academia de Buenas Letras de Barcelona» VIII (1915) págs. 226-233; está citado en RoMANO, Les juifs de Catalogne, doc. $\mathrm{n}^{2} 4$.

9 Ejemplos de ello se encuentran en Romano, Les juifs de Catalogne, doc. 7 (año 987): en J. M." Millás VAllicrosa, Escrituras mozárabes de hebreos toledanos (en A. González Palencia, Los mozárabes de Toledo en los siglos XII y XIII, Madrid 1928, vol. III), doc. nos 1132, 1133 y 1136; y en B. LEROY, Les juifs et le monde rural, pág. 86. 
Sin duda una de las maneras de poseer tierras es obtenerlas por compra, pero también pueden haberse recibido por donación ${ }^{10} \mathrm{O}$ por herencia ". Ahora bien, creo que es lícito pensar al menos en otro medio de adquisición, que por ahora sólo expongo a título de hipótesis: el que deriva de tierras dadas como prenda o garantía de un préstamo, y que podían cambiar de propietario como consecuencia de impago de la deuda ${ }^{12}$. Pero la verdad es que esas "transacciones», mejor dicho, el resultado de esas "transacciones» deja poco rastro. Sería de agradecer toda información concreta, documental, sobre este tema.

Otra cuestión a profundizar es la procedencia de las tierras. La propiedad por herencia sólo puede venir de otro judío; la propiedad consecuencia indirecta de préstamo sólo llega de cristiano - recuerdo que el judaísmo prohíbe el préstamo a judíos ${ }^{13}-$, mientras que la adquisición y la donación pueden proceder tanto de judío como de cristiano. Pero los documentos no siempre aclaran la cuestión, pues a veces sólo nos consta la propiedad de una manera indirecta: así, por ejemplo, gracias a una "carta evacuacionis", es decir, reconocimiento de un derecho o posesión entregado por la parte que ha perdido un pleito ${ }^{14}$.

\subsection{Tipos de tierras ${ }^{15}$}

Un documento del año 1000 menciona genéricamente en Barce-

\footnotetext{
10 Véase $\$ 1.4$ y el texto copiado al final del $\S 2.2$.

$"$ Romano, Les juifs de Catalogne, doc. ne 4 (año 973) y doc. n² 20 (año 1010).

${ }^{12}$ En un documento del 23.6.1018 Ramio y su mujer Castelana se declaran «impignoratores sumus tibi Bonum Nomen ebreo. Manifestum est enim quia debitores sumus tibi mancusos VII de auro cocto iaharis aut amoris a penso de tuo domo quod tu nobis prestasti» y añaden «impignoramus tibi casa et curte... et terra cum orto et arboribus". Más adelante concretan "et si non adimplerimus... habeas plenam potestatem predicta ea omnia aprendere, tenere, vindere et facere quod volueris" (Archivo de la Corona de Aragón pergamino de Berenguer Ramón I $\mathbf{n}^{\mathbf{1}}$ 14). Al dorso hay un breve texto en hebreo que no consigo leer. Véase B. LEROY, The Jews of Navarre in the Late Middle Ages, Jerusalem 1985, págs. 41 y 70-71.

13 Véase D. Romano, Prestadores judios en los estados hispánicos medievales, «Estudios Mirandeses" VIII (1988) 117-126.

14 Romano, Les juifs de Catologne, doc. $\mathrm{n}^{2} 21$.

15 Para todo lo que voy a decir, véase Romano, Habitats, $\$ 1.2 .1 .2$, apartado que trata de los tipos de terrenos.
} 
lona "terras et vineas» ${ }^{16}$, conjuntamente y sin distinguir las unas de las otras; pero los documentos mismos señalan la diferencia, pues unas veces hablan de tierras y otras de viñas, y dudo mucho que se trate de una simple distinción léxica. Todos sabemos para qué sirven las viñas; en cambio, quisiéramos saber a qué se dedicaban las tierras. Creo que debe tratarsé de campos, o más bien de huertas, pero es una hipótesis no documentada, por ahora al menos.

El problema resulta todavía más complejo cuando los documentos hablan de "alodios", pues es una palabra que realmente no indica un tipo de terreno ${ }^{17}$ sino la forma de posesión jurídica: en otras palabras, los alodios deben ser también viñas o tierras, pero en cuanto no sujetas a cargas señoriales (en oposición al feudo).

A las veces los documentos de la época ofrecen otras nomenclaturas, que no me atrevo a definir, al menos por ahora. Por ejemplo, en pergaminos de Barcelona fechados hacia el año 1000 existen menciones de "solario judayco", "terra judayca" y "villa judaica»; y documentos también barceloneses del siglo XIII hablan de molinos construidos ante la «trilla judaica» ${ }^{18}$.

Además, sin pretensiones de exhaustividad, hay noticias de más tipos de tierras. En Valtierra (Navarra) en 1188 se habla de "vinnas, peças, ortos, areas, erbas" ${ }^{19}$; en el siglo XIV en varias localidades de Navarra se mencionan viñas, piezas (quizás terrenos dedicados al cultivo de cereales) y huertos ${ }^{20}$; en Huesca en 1340 hay "vinnas,

\footnotetext{
16 Romano, Les juifs de Catalogne, doc. $\mathrm{n}^{2} 13$.

17 Me equivoqué al considerarlo como un tipo de terreno (Romano, Les juifs de Catalogne, \& 1.2.1.2).

${ }^{18}$ Entre los documentos conocidos véanse los que publica C. Batlle I Gallart, La casa burguesa en la Barcelona del siglo XIII, en "La societat barcelonina a la Baixa Edat Mitjana» ("Acta Mediaevalia, annex I", Barcelona 1982-1983), págs. 12-13 y docs. nos 4 -lleva la fecha equivocada- y 6. Véase también el fragmento que figura en BAER, JCS $\mathrm{I}, \mathrm{n}^{0} 622$. Trilla es un huerto de regadío, cercado y próximo a la ciudad (v. J. Balari y Jovany, Orígenes históricos de Cataluña, Barcelona 1899, pág. $619=$ reedición del Instituto Internacional de Cultura Románica, San Cugat del Vallés 21964, págs. 650-651).

19 B. LeROY, The Jews of Navarre, pág. 39 nota 14.

20 J. Carrasco Pérez, Los judíos de Viana y Laguardia (1350-1408): aspectos sociales y económicos, en "Vitoria en la Edad Media" Vitoria-Gasteiz 1982, págs. 423-425; Propiedades de judíos en la merindad de Estella (1330-1381), en “Estudios en memoria del Profesor D. Salvador de Moxó» I, Madrid 1982, págs. 278-282; Bienes raices de judios en Tudela y su merindad (1348-1381), en "Proceedings of the Ninth World Congress of Jewish Studies, division B, vol. I: The History of the Jewish People», Jerusalem 1986, págs. 98-99.
} 
campos, tiendas, parrales, huertos» ${ }^{21}$; en el sur de la Península son frecuentes los olivares ${ }^{22}$; alguna vez se citan tierras de baldío ${ }^{23}$.

\subsection{Las tierras en los Repartimientos}

No hay datos sobre grandes propiedades agrícolas judías, quizás simplemente porque no las hubo ${ }^{24}$. En este aspecto parece que tiene cierto peso el argumento parcialmente negativo que ofrecen los Repartimientos, aunque la verdad es que debieran estudiarse con calma y cuidado: los datos apuntan más bien a propiedades de tamaño medio (por no decir pequeñas).

Cronológicamente, el primero de esos Repartimientos es el de Mallorca (1232) en el que algunos judíos - sólo deben tomarse en consideración las personas explícitamente denominadas judíos- obtienen pequeños terrenos, de la misma extensión que los cristianos (excepto los cuatro grandes colaboradores del Rey). El único beneficiario relativamente grande es el grupo de judíos de la Almudaina (el barrio judío de Palma), a quienes se les dan: en Palma $6+4+4$ yugadas, en Sineu $8+5$ yugadas y en Montuiri $5+8$ yugadas ${ }^{25}$.

En el Repartimiento de Valencia (1238) suelen concedérseles de 2 a 4 yugadas, aunque hay un caso excepcional en que a un judío se le dan 22 yugadas ${ }^{26}$.

En el de Sevilla (1253) los beneficiarios consiguen 20, 50 ó 100

${ }^{21}$ BAER, JCS I, pág. 288, 3.

${ }^{22}$ Por ejemplo, en el Repartimiento de Sevilla, al que aludiré en el $\S 1.4$.

23 J. M.' Millás Vallicrosa, Escrituras, n² 1140.

${ }^{24}$ Véase el razonamiento de J. M.' Monsalvo Antón, Cortes de Castilla y León y minorlas, en "Las Cortes de Castilla y León en la Edad Media», Valladolid 1988, págs. 160-162.

${ }^{25} \mathrm{~J}$. BusQuets Mulet, El códice latinoarábigo del Repartimiento de Mallorca (parte latina), "Boletín de la Sociedad Arqueológica Luliana" XXX (1947-1952) págs. 719, $725,732-733$ (correspondientes a los folios $5 \mathrm{r}, 8 \mathrm{v}$ y 13v del manuscrito). No se les menciona en el texto árabe, editado por J. BUSQUETS MULET, El códice latinoarábigo del Repartimiento de Mallorca (texto árabe), en "Homenaje a Millás-Vallicrosa" I, Barcelona 1954, págs. 243-300.

$26 \mathrm{~J}$. RÉGNE, History of the Jews in Aragon. Regesta and Documents 1213-1327, Jerusalem 1978, reimpresión del Catalogue des actes de Jaime Ier, Pedro III et Alfonso III rois d'Aragon, concernant les juifs (1213-1291) y del Catalogue d'actes pour servir d l'histoire des juifs de la Couronne d'Aragon sous le règne de Jaime II (1291-1327), publicados en la "Revue des Études Juives" a partir del volumen LX (1910) doc. $\mathrm{n}^{\mathrm{a}}$ 15. 
aranzadas de olivar ${ }^{27}$, una extensión mayor por tratarse de cultivo arbóreo de secano.

Desconozco citas en otros repartimientos ${ }^{28}$. .

\section{El CULTIVO DE LAS TIERRAS}

\subsection{Consideraciones generales}

Estas propiedades plantean un agudo interrogante: ¿sus propietarios judíos se dedicaban a la vida agrícola, eran agricultores? Esta afirmación se ha hecho muy a menudo, precisamente basándose en la posesión de tierras; pero tengo la impresión de que esas tierras y viñedos (todos en las proximidades de núcleos urbanos) eran cultivados subsidiariamente, quiero decir, cuando el judío había concluido su trabajo artesano que más que probablemente era su principal ocupación: valdría la pena reflexionar sobre el hecho de que esos trabajos artesanos dejan escasos rastros archivísticos ${ }^{29}$.

Efectivamente, poseer tierras no quiere decir cultivarlas, ni personalmente ni por medio de asalariados (que no suele haber). Como indicaré más adelante $(\S 2.2)$, las pruebas evidentes de cultivo por judíos son bastante raras.

El argumento esgrimido con mayor frecuencia para sostener el cultivo por judíos se refiere a las viñas, que serían necesarias para obtener vino kašer. Esto no es cierto porque para hacer vino kašer ("vino judiego", "vino judienco", "vi juesc») ${ }^{30}$ no es necesario cultivar las viñas. La kašrut no depende del cultivo de la viña sino sólo de la elaboración y de la conservación del vino. $\mathrm{Y}$ hay pruebas manifiestas de ambas cosas.

En cuanto a la elaboración recordaré dos aspectos. Es posible 1) comprar la uva a los cristianos, incluso sobre viña, y así se hacía: he recogido numerosos testimonios de los judíos del siglo XIV en el

27 BAER, JCS II, n 67. Una aranzada son 447 deciáreas, o sea, 44,7 áreas.

${ }^{28}$ Del Repartimiento de Jerez (1266) sólo se conserva la parte referente a las casas (BAER, JCS II, n 76; en todo caso, habría de consultarse la edición de GonZÁleZ).

${ }^{29}$ Traduzco de Romano, Les juifs de Catalogne, $\$$ 1.2.1.2.

${ }^{30}$ Es falso lo que dije en D. Romano, Figurantes judios en representaciones sacras (Villarreal, siglos XIV y XV), "Sefarad» XXIX (1969) 75-76: el hecho de que no bebieran vino judiego es prueba indudable de que los figurantes no eran judíos. 
Archivo Histórico de Protocolos de Barcelona, en especial en los notarios Pere Pujol y Bonanat Rimentol; el llorado Leopoldo Piles señaló ejemplos en el reino de Valencia ${ }^{31}$; para Navarra recuerdo datos del siglo XIV ${ }^{32}$ y para Mallorca un reglamento de 1401 especifica cómo han de pagar la sisa del vino los judíos que compren «verema per fer vi jueu» ${ }^{33}$. Por otra parte 2) está prohibida la adición de agua, cal o yeso ${ }^{34}$.

En cuanto a la conservación del vino, para evitar manipulaciones que lo harían no apto para el consumo, un ejemplo podría ser suficientemente ilustrativo: en 1367 Astrug Botarell, mercader judío de Barcelona, envía a Marsella mercaderías y vino en una barca en la que irán dos judíos como guardianes, del vino naturalmente (pues los bienes en general no precisan vigilancia constante) ${ }^{35}$.

\subsection{Propiedades de tamaño medio: explotación ganadera}

Ya he señalado ( $\S 1.4)$ que, si los hubo, no quedan datos acerca de grandes propiedades agrícolas judías. Y solamente unos cuantos de terrenos de mediana extensión. Con todo, yo diría que los terrenos de cierta extensión no parece que se dedicaran a la agricul-

${ }^{31}$ La última vez fue en su intervención a la ponencia de Y. T. Assis en el Congreso de "Història dels jueus a Catalunya" (Gerona 23-25 abril 1987), cuando dijo: “Los que sí aparecen con gran frecuencia son los compradores de la 'verema' del vino" (en "Jornades d'Història dels jueus a Catalunya, Girona abril 1987" Girona 1990, pág. 167.

${ }^{32}$ Véase el documento de 1365 publicado por BAER, JCS I, $\mathrm{n}^{\circ}$ 593, así como los datos aportados por B. LEROY, Recherches sur les juifs de Navarre d la fin du Moyen $\hat{A} g e$, «Revue des Études Juives» CXL (1981) pp. 341-342, traducido en el libro conjunto de M. GARCIA-ARENAL y B. LeROY, Moros y judios en Navarra en la Baja Edad Media, Madrid 1984, págs. 163-164.

${ }^{33}$ A. SAntamaría, Sobre la aljama de Mallorca: el impuesto "sizé del vin juheuesch", 1400-1435, en "En la España medieval», Madrid 1981, pág. 477.

34 Véase A. Blasco MARTínez, La producción y comercialización del vino entre los judios de Zaragoza (siglo XIV), que se publicará en el «Anuario de Estudios Medievales" § 0 . y también $\S 2$., titulado "La compra de la uva en la cepa". Se trata del primer estudio amplio del tema, en el que junto a problemas concretos se hacen observaciones de valor general.

${ }^{35}$ He aquí la frase: «Item promet lo dit patró al dit mercader que ell lavarà en la dita barcha dos homens juheus axi en Barchinona com en Maçella los quals sien guardes del vi e de les robes del dit mercader e no pus avant" (Archivo Histórico de Protocolos de Barcelona, notario Pere Martí: Manual 6.2.1367-15.10.1367, fols. 63v65). 
tura sino a la explotación ganadera. Hay ejemplos en Tudela (1383, 1393) ${ }^{36}$, pero quizá el caso más singular sea el de Jahudán de Cavallería ${ }^{37}$, poseedor de un terreno (o territorio) en el que en 1273 sus exáricos podían apacentar hasta 1000 cabezas de ganado.

Ahora bien, ni en un caso ni en otro consta que fueran judíos los encargados materiales del pastoreo.

\subsection{Pequeños cultivadores judíos}

En cambio, sí hay noticias dispersas de pequeños cultivadores, aunque no sean muy abundantes ${ }^{38}$. La mayoría de ejemplos son de Aragón: Serrano y Sanz, que trabajó sobre todo con los protocolos zaragozanos del siglo $\mathrm{XV}{ }^{39}$, afirmó que «sólo he tropezado con un judío labrador» (de 1457) y la gran investigación (en tiempo, cantidad, sistematización y resultados) de Asunción Blasco ${ }^{40}$ únicamente ha dado a conocer la existencia de dos documentos -únicamente dos- positivos sobre el tema. Uno es un contrato (1347) por el que tres cristianas

«damos a lavrar a vos don Juhuda Almali... una vinnya... dius tal condicion que vos que cavedes la dita vinnya en cada un anno dos vegadas";

el otro es un contrato de aprendizaje (1399):

«Habraham Gascon... firmome... por mancebo e servidor al oficio e art de la agricultura siquiera lavradoria».

Estos ejemplos proceden del reino de Aragón. Pero eso no

36 Véase B. LEROY, Les juifs et le monde rural, págs. 84-85.

37 F. DE A. DE Bofarull y SANS, Jaime I, pág. 835 y doc. $\mathrm{n}^{\circ} 127$. Este documento está ausente en el repertorio de Régné (citado en mi nota 31), pero sí estaba recogido en el de Jacobs (doc. $\mathrm{n}^{\circ}$ 525). Véase D. Romano, Análisis de los repertorios documentales de Jacobs y Régné, "Sefarad"XIV (1954) 247-264.

38 Véase lo que he dicho en Romano, Habitats, $\$ 1$.

39 M. Serrano y SAnz, Origenes de la dominación española en América. Estudios históricos, Madrid 1918, pág. XXXVIII nota 1: el 15.11.1457 "Salamon Alhaquim, lavrador».

40 A. Blasco, Los judios de Zaragoza en el siglo XIV, tesis doctoral aún inédita. Los documentos que citaré a continuación están fechados en 7.11.1347 y 22.6.1399. 
significa que sean los únicos ni que únicamente los hubiera en dicho estado. Así, entre noticias que quizás no sean todo lo evidentes que se quisiera, en 1193 el comendador (del Temple) de Miravet y Tortosa hace donación a dos mudéjares y al judío Jucef Cornela en una "alcira» (llamada "inter ambas aquas») de una

«terra culta et herema et platea et omnibus arboribus diversos generes... ad quartum... et laborandum per secula cuncta" para que los «melioretis et laboretis» ${ }^{41}$;

en un documento de 1310 consta que a Anoch Zabarra, judío de Cardona (Cataluña), se le hizo un "establecimiento" ${ }^{42}$ de dos lotes de tierra y viña, a cambio de un censo anual de 5 sueldos barceloneses ${ }^{43}$; en 1294 en Miranda de Ebro cuatro judíos no asisten a una reunión porque "eran ydos a laurar a las aldeas" ${ }^{44}$; y en 1443 dos matrimonios judíos de Talavera de la Reina se obligaron a hacer las labores de una viña del cabildo y a echar cada año dos azadones de mugrones o cepas de cabeza ${ }^{45}$; y en 1478 se arrendó una viña que normalmente trabajaba Alubo, judío de Calahorra ${ }^{46}$.

Más general es la afirmación de que en los responsa de $\mathrm{R}$. Šlomó ben Adret «encontramos referencias precisas sobre judíos propietarios de tierras que se dedicaban a su cultivo y que ocupaban en ellas mano de obra asalariada. Las fuentes no precisan, sin embargo, si se trataba de mano de obra judía o cristiana» ${ }^{47}$. Asi-

${ }^{41}$ Archivo de la Corona de Aragón, pergamino de Alfonso I nos 663 y 663 duplicado.

42 En Cataluña es la denominación usual de la enfiteusis.

${ }^{43}$ M. Mituans, Index $i$ recopilació de tots los actes, manuals, llibres y escripturas del arxiu del illustre Capitol de la iglesia secular y collegiata molt insigne de Sant Vicens de Cardona (1721), conservado en el Archivo Diocesano de Solsona, perg. 702 (25.3.1310). Agradezco la noticia a mi amiga Montserrat Casas.

44 F. Cantera, La judería de Miranda de Ebro (1099-1350), "Sefarad" I (1941) doc. I (pág. 112). Este texto me fue recordado en Jerusalén por José Luis Lacave: se lo agradezco mucho.

45 P. León Tello, Judíos de Toledo, tomo II, Madrid 1979, pág. 244 (doc. n 812).

46 E. Cantera Montenegro, Actividades socio-profesionales de la población hebrea en Calahorra, en "Calahorra. Bimilenario de su fundación. Actas del I Symposium de Historia de Calahorra", Madrid 1984, pág. 353.

${ }^{47}$ Y. T. Assis, La participación de los judíos en la vida económica de Barcelona s. XIII-XIV, en "Jornades d'Història dels jueus a Catalunya, Girona abril 1987», Girona 1990, pág. 82, pero cf. pág. 166. 
mismo, un texto hebreo de fines del siglo XIV ${ }^{48}$, explica que los judíos de la comunidad de Montalbán están en los campos ocupados en la cosecha. Con todo, según mis conocimientos, la prueba colectiva más destacada sobre este asunto es la afirmación de que en 1436 en Huesca

«judei dicte civitatis pro magna parte laboratores sive cultivatores agrorum et vinearum existant" ${ }^{49}$.

\section{3 ¿Fue la agricultura ocupación principal de los judíos?}

Y eso me lleva a plantear la cuestión de saber si el sector primario era ocupación principal de los judíos en la Edad Media hispánica (como lo había sido en tiempos bíblicos y lo es hoy en Israel). Mi respuesta es negativa, y sólo cuando se hayan recopilado noticias positivas podré cambiar de opinión.

Mi opinión es que la agricultura era una ocupación subsidiaria pero no principal: más que probablemente la causa básica de ello radica en el peligro que supone el aislamiento.

3. LA RESIDENCIA RURAL

\subsection{Preliminares}

Por razones de «seguridad", por el peligro del aislamiento, el hábitat judío ha de ser exclusivamente urbano. No existe, al menos yo no conozco ningún documento que pruebe la posibilidad o la realidad de un hábitat disperso, de un judío que resida en una casa de campo o en el campo.

\subsection{Inexistencia de población rural judía}

Como he dicho en otras ocasiones, es innegable que "poseer no significa habitar». En ningún caso los documentos históricos que conozco hablan de casas habitadas por judíos en el campo y los

48 BAER, JCS 1, pág. 727: מפני העם שבשדות יצאו ללקוט.

49 BAER, JCS I, $\mathrm{n}^{2} 535$ (el subrayado de la expresión, en cursiva, es mío). 
textos no documentales aducidos ${ }^{50}$ a mi parecer realmente no demuestran que se trate de hábitats rurales. Si he comprendido bien, los textos hablan de כפר תוך חומות העיר o bien de עאין בה עשרה בני אדם. En un caso y en otro, la palabra עיר שור me resulta negativamente significativa para la cuestión que estoy analizando.

Con todo, creo que quizás hubiera que hacer si no una búsqueda sistemática al menos una recopilación de casos.

\subsection{Falsedad de las huellas de la toponimia}

Un último punto a tratar es el de la toponimia que, según algunos, demostraría inequívocamente la presencia judía en el campo. Es evidente que también en esta cuestión debiera hacerse una investigación apurada, aunque estoy convencido de que conduciría a resultados francamente negativos: sin entrar en problemas filologicolingüísticos, así parecen indicarlo la mayoría de los casos que conozco. En esta ocasión me limitaré a Cataluña.

Positivo, para algunos con reservas, es el topónimo Montjuic(h), que sería un Mons judaicus, monte ${ }^{51}$ existente al menos en Barcelona y en Gerona. Para Barcelona el hallazgo del cementerio judío ${ }^{52}$ abona favorablemente la hipótesis, cosa que no puede decirse de Gerona, al menos por ahora y hasta que se hayan hecho las excavaciones que sugerí en su día ${ }^{53}$.

Los topónimos con un elemento judío («judaicus, judaica, jueu») son sólo eso: topónimos. Al referirse a "villa judaica", "allodium judaicum» y "mons judaicum», Baer ${ }^{54}$ afirmó que "no podemos dilucidar si se llamaban así porque sus propietarios eran judíos $o$

${ }^{50} \mathrm{M}$. KrIEgel, Les juifs à la fin du Moyen Âge dans l'Europe méditerranéenne, Paris 1979, pág. 257, nota 16 que cita a R. Šlomó ben Adret (Responsa vol. I, nos 638 y 1167).

${ }^{51}$ He de observar que el topónimo, sin duda con muy distinto sentido, subsiste en plena ciudad: hay una calle que se llama Montjuich del Bisbe y otra Montjuich del Carme.

52 Véase A. Durán Sanpere i J. M.a Millás Vallicrosa, Una necrópolis judaica en el Montjuich de Barcelona, "Sefarad" VII (1947) 231-259.

${ }^{53}$ Lo sugerí en la ponencia de clausura del congreso celebrado en Gerona: D. Romano, Primer balanf valoratiu de les «Jornades", en "Jornades d'História dels jueus a Catalunya, Girona abril 1987", Girona 1990, págs. 341-342.

${ }^{54}$ Y. F. BAER, Historia de los judios en la España cristiana, trad. J. L. LACAVE, Madrid 1981, pág. 34 y la nota 4 de la pág. 670. 
porque lo eran sus habitantes». Pero yo añadiría: «o por otra razón que se nos escapa", aunque se trate de voces nacidas hace más de 500 años y con una significación muy precisa. Los ejemplos más conocidos son Vilajuïga y Matajudaica, pero también hay que recordar Judaicas $>$ Juigas/Juigues ${ }^{55}$, los tres en la actual provincia de Gerona; y la Turre de iudeo/iudea, documentada en 1160 en la provincia de Barcelona ${ }^{56}$.

Entre los ejemplos pirenaicos, en zona lingüística aranesa, recuerdo: la vall del Jueu, cerca del lago de Estangento, a más de 2000 $\mathrm{m}$ de altitud, en una zona que jamás ha sido poblada; y el manantial (güell) y riachuelo $J u e u$, en el valle de Arán.

Pero el desencanto mayor -icuidado con las acechanzas de la filología!- es el siguiente: en Sant Gregori (municipio al NW de la ciudad de Gerona) existen dos masías que se conocen con la denominación de Jueria grossa y Jueria petita. La presencia del vocablo jueria como derivado de jueu en una zona histórica en que las juderías se llaman call ${ }^{57}$ ya resulta extraño; pero, además, documentos del siglo XVI hablan de joheria, palabra derivada de jouers/jovers, o sea, "yugueros", aparceros ${ }^{58}$.

La tendencia a «judaizar» llega a ser tal que el nombre de la población de Palol de Reverdit (Gerona) la etimología popular lo hace derivar de "Palaciolo de rivo Davidi", es decir, "palacete del rey David" ${ }^{59}$.

\section{CONCLUSIONES}

He aquí los resultados alcanzados en esta propuesta de trabajo:

${ }^{55}$ Es un alodio del antiguo condado de Besalú con judíos quizás en el siglo IX. Véase Romano, Les juifs de Catalogne, $\S 0.5$.

${ }^{56}$ Cartulario de "Sant Cugat» del Vallés, vol. III (ed. J. Rius Serra, Barcelona 1947, doc. $\mathrm{n}^{2} 1033$ (págs. 202-203). Agradezco la noticia al Dr. Albert Benet i Clarà.

57 D. Romano, Aljama frente a juderla, call y sus sinónimos, "Sefarad" XXXIX (1979 [1981]), 347-354.

58 Véase J. Calzada, Sant Gregori, Girona 1986, págs. 189-198, capítulo titulado "La Joheria de Sant Gregori». Pero la tradición, y los mapas de carreteras, siguen escribiendo Jueria.

${ }^{59}$ En la obra de J. L. y J. Villanueva, Viage literario a las Iglesias de España, vol. XII, apéndice XXXII hay un documento del año 1116 que menciona el arroyo "rivolum qui dicitur Rio David». 
1. Está demostrado que los judíos poseían tierras y huertos, viñas y olivares, en general pequeños, adquiridos por compra, por herencia, por donación y quizás como resultado de impago de un préstamo.

2. Parece que el cultivo se hacía en pequeños terrenos, y que no era una ocupación principal sino subsidiaria. Las pocas zonas 'grandes' propiedad de judíos estaban dedicadas a la ganadería.

3. No hay absolutamente ninguna prueba de hábitat rural judío, y las huellas de la toponimia son falaces.

Insisto - creo que es el error más frecuentemente repetido- en que poseer no significa forzosamente cultivar ni habitar en el terreno que se posee.

\section{RESUMEN}

Intento de planteo sistemático de las cuestiones acerca de la relación de los judíos hispánicos con el campo y la vida rural a base de ejemplos documentales (en especial de la Corona de Aragón), con las siguientes conclusiones: los judíos poseían tierras, en general de reducida extensión; algunas veces las cultivaban personalmente, pero la agricultura era ocupación subsidiaria; no hay ninguna prueba de hábitat rural judío.

\section{SUMMARY}

This is a tentative approach to systematize, through documentary evidence, the study of the relations of the Spanish Jews with the countryside and rural areas (particularly in the Crown of Aragon), from which the following conclusions may be drawn: the Jews owned land property, generally not very large, which they sometimes cultivated; notwithstanding, agriculture is not recorded as a noteworthy activity among Jews; no evidence has been found of any Jewish rural habitat. 